\title{
Методика геоэкологического мониторинга хранилища отходов обогащения редкометальных руд Карнасуртского месторождения (ООО «Ловозерский ГОК», Кольский полуостров)
}

\author{
Горячев А.А. ${ }^{1}$, Лащук В.В. ${ }^{2}$, Мартынов Е.В. ${ }^{3}$ \\ ${ }^{1}$ ПТТБА КНЦ РАН, Anamumbl, andrej.goria4ev@yandex.ru \\ ${ }^{2}$ ИХТРЭМС им. А.В. Тананаева ФИЦ КНЦ РАН, lashchuk@chemy.kolasc.net.ru \\ ${ }^{3}$ Геологический институт КНЦ РАН, Anamumbl, mart@geoksc.apatity.ru
}

\begin{abstract}
Аннотация. Разработана методика геоэкологического мониторинга хранилищ отходов обогащения редкометальных руд на примере хвостохранилища Ловозерского ГОКа. Проведены комплексные лабораторные исследования серии технологических проб, отобранных по профилю поверхности этого техногенного образования. При помощи факторного анализа методом главных компонент установлены основные показатели минерального состава и структуры, которые влияют на инженерно-геологическое, геохимическое и радиационное состояние мелкозернистого пылеватого грунта.
\end{abstract}

Ключевые слова: хвостохранилища, отходы обогащения, редкометальные руды, факторный анализ методом главных компонент, оценка: инженерно-геологическая, геохимическая, радиационная.

\section{The method of geoecological monitoring of tailing dumps of enriched rare metal of the Karnasurt deposit (Lovozersky GOK, Kola Peninsula)}

\author{
Goryachev A.A. ${ }^{1}$, Lashchuk V.V. ${ }^{2}$, Martynov E.V. ${ }^{3}$ \\ ${ }^{1}$ NTTSA KSC RAS, Apatity, andrej.goria4ev@yandex.ru \\ ${ }^{2}$ ICTREMR I.V.Tananaev KSC RAS, lashchuk@chemy.kolasc.net.ru \\ ${ }^{3}$ Geological Institute of KSC RAS, Apatity, mart@geoksc.apatity.ru
}

\begin{abstract}
The method of geoecological monitoring of enriched rare metal ore tailing dumps has been developed. The complex laboratory studies of a series of technological samples selected on the surface profile of this technogenic formation have been carried out. Using the principal component analysis, the main indicators of the mineral composition and structure, which affect the engineering-geological, geochemical and radiation state of finegrained soil, have been established.

Key words: tailing dumps, enrichment wastes, rare metals ores, principal component analysis, engineeringgeological and radiation assessment.
\end{abstract}

\section{Введение}

Мурманская область является регионом с крупнейшими предприятиями минеральносырьевого комплекса. На территории региона ежегодно складируется более 150 млн. т. отходов горного, обогатительного и металлургического производств (Доклад о состоянии..., 2018). Разработка и внедрение эффективных методов предотвращения их негативного воздействия на окружающую среду и переработки отходов актуально как для Российской Федерации, так и для других стран (Lottermoser B.G., 2011).

ООО «Ловозерский ГОК» - ведущее отечественное предприятие по производству концентратов редкоземельных металлов. Здесь на руднике «Карнасурт» производится добыча и обогащение руды с получением лопаритового и эвдиалитового концентратов (Пожиленко и др. 2002).

Особенность сырья заключается в том, что оно имеет повышенный радиационный фон. Комбинат расположен у подножья горного массива Ловозерские тундры, а в нескольких километрах на север от него располагается Ревда. Таким образом, в пределах изучаемой территории на природную среду оказывают влияние разные по масштабу, степени и характеру воздействия производства, селитебной территории и автотранспорта. 


\section{Методика исследований}

Для геоэкологической оценки хранилищ отходов обогащения руд, как правило, используется комплекс исследований (Лащук и др., 2008).

В методическом плане хранилище отходов обогащения руд мы рассматриваем как инженерногеологическое тело несвязных грунтов, как потенциальный и дополнительный источник полезных минеральных компонентов. Использование их, например, для производства заполнителей бетона, строительной керамики, позволит снизить отрицательное воздействия на окружающую среду (Лащук и др., 2011).

Инженерно-геологические характеристики хвостов обогащения лопаритовых руд определялись по ГОСТ 5180. Содержания удельных радиационных активностей изотопов ${ }^{226} \mathrm{Ra},{ }^{232} \mathrm{Th}$ и ${ }^{40} \mathrm{~K}$ и общая эффективная активность технологических проб ООО «Ловозерский ГОК» определялись и расчитывались в Лаборатории регионального радиационного контроля ИХТРЭМС в соответствии с ГОСТ 30108.

На основании анализа ранее проведенных исследований разработана следующая последовательность изучения отходов обогащения руд Кольского региона:

- опробование поверхности пляжа хранилища;

- комплексные исследования состава, структуры и физико-химических свойств техногенного несвязанного грунта;

- изучение распределения показателей по территории объекта;

- оценка изученных показателей по средним значениям;

- выявление основных показателей минерального состава и структуры, влияющих на свойства техногенного образования;

- разработка рекомендаций по переработке отходов для производства строительных и технических материалов с целью снижения этих образований на окружающую среду.

\section{Результаты}

В настоящей работе представлены результаты комплексных исследований отходов обогащения, которые отобраны в мае 2018 года по профилю поверхности хранилища редко метальных руд Карнасуртского рудника (табл. 1).

По гранулометрическому составу - это однородный, пылеватый песок (Ломтадзе, 1984). Он включает преимущественно фракции 0.5-0.25 и 0.25-0.10 мм (32.8 и 47.8 мас. \%), коэффициенты вариации этих значений 0.34 и 0.16. Менее представительная фракция 0.1-0.05 мм, составляющая 10.6 мас. \% - не выдержанная, коэффициент вариации составляет 0.71.По величине коэффициента пористости ( $(\varepsilon)$ пробы варьируют от плотных грунтов до грунтов средней плотности (ГОСТ 25100).

Средние значения средней и истинной плотности составляют соответственно 1.93 и 2.78 г $/ \mathrm{cm}^{3}$. Средняя влажность песчаной толщи 22 мас. \%, коэффициент вариации 0.59. Это свидетельствует о высокой неоднородности водных потоков. Поровые растворы слабощелочные - среднее значение $\mathrm{pH}$ составляет 9.4. Общая эффективная активность естественных радионуклидов в среднем составляет 842 Бк/кг, что соответствует 3-му классу радиоактивности строительных материалов, которые можно использовать в дорожном строительстве вне населенных пунктов (ГОСТ 30108).

По минеральному составу изучаемые отходы обогащения редкометальных руд близки к вмещающим луявритам и имеют мезократовый облик. Главными породообразующими минералами являются кали-натровые полевые шпаты, нефелин, амфибол (арфведсонит), меньше - пироксен (эгирин). Средние содержания этих минералов соответственно составляют 40.7, 21.7, 21.5, 13.5 мас. \%. Пироксен и редкие рудные минералы - лопарит, эвдиалит характеризуются высокой невыдержанностью среднего содержания, о чем свидетельствуют коэффициенты вариации значений в диапазоне $0.50-1.25$.

Результаты обработки данных полевых и лабораторных исследований обрабатывались математическими методами корреляционного и многопараметрического факторного анализа методом главных компонент (фа МГК) (табл. 2). 
Таблица 1. Гранулометрический и минеральный составы, физико-химические свойства отходов обогащения редкометальных руд Карнасуртского рудника.

Table 1. Partical size distribution, mineral composition, physicochemical properties of the enriched Karnasurt deposit rare metal ores.

\begin{tabular}{|c|c|c|c|c|c|c|c|c|}
\hline \multirow{3}{*}{$\begin{array}{c}\text { Статистические } \\
\text { показатели }\end{array}$} & \multicolumn{4}{|c|}{ Физико-химические свойства } & \multicolumn{4}{|c|}{ Гранулометрический состав, фракция, мм } \\
\hline & \multicolumn{2}{|c|}{$\begin{array}{c}\text { Плотность, } \\
\rho_{\text {ист }} \text { и } \rho_{\mathrm{cp}}, \Gamma / \mathrm{cm}^{3} \\
\end{array}$} & \multirow{2}{*}{$\begin{array}{c}\text { Влажность, } \\
\text { W, мас. } \%\end{array}$} & \multirow{2}{*}{$\begin{array}{c}\mathrm{pH} \text { порового } \\
\text { раствора }\end{array}$} & \multirow[t]{2}{*}{$1.0-0.5$} & \multirow[t]{2}{*}{$0.50-0.25$} & \multirow[t]{2}{*}{$0.25-0.10$} & \multirow[t]{2}{*}{$0.10-0.05$} \\
\hline & истинная & средняя & & & & & & \\
\hline Среднее & 2.78 & 1.93 & 22 & 9.38 & 5.1 & 32.8 & 47.8 & 10.6 \\
\hline $\begin{array}{l}\text { Доверительный } \\
\text { интервал }\end{array}$ & $2.76-2.80$ & $1.87-1.99$ & $17-27$ & $9.18-9.58$ & $4.1-6.1$ & $29.0-36.6$ & $45.2-50.4$ & $8.3-13.3$ \\
\hline Коэф. вариации & 0.02 & 0.09 & 0.59 & 0.06 & 0.59 & 0.34 & 0.16 & $0.71^{2}$ \\
\hline
\end{tabular}

\begin{tabular}{|c|c|c|c|c|c|c|c|c|c|c|}
\hline \multirow{3}{*}{$\begin{array}{l}\text { Статистические } \\
\text { показатели }\end{array}$} & & & & & & & \multicolumn{4}{|c|}{ Продолжение таблицы 1.} \\
\hline & \multicolumn{6}{|c|}{ Минеральный состав, мас.\% } & Содерж & $\begin{array}{l}\text { ние раді } \\
\text { Бк/кг }\end{array}$ & онуклидов, & Аэ $\phi^{4}$, \\
\hline & Fsp & $\mathrm{Ne}$ & Am & Px & Lop & Evd & Ra-226 & Th-232 & $\mathrm{K}-40$ & \\
\hline Среднее & 40.7 & 21.7 & & 13.5 & 1.7 & 0.6 & 137 & 459 & 1200 & 842 \\
\hline $\begin{array}{l}\text { Доверительный } \\
\text { интервал }\end{array}$ & $38.0-44.4$ & $19.7-24.3$ & $18.6-24.3$ & $11.1-15.8$ & $1.4-2.0$ & $0.4-0.8$ & $130-145$ & $420-499$ & $1171-1229$ & $785-898$ \\
\hline Коэф. вариации & 0.21 & 0.32 & 0.39 & 0.50 & 0.59 & 1.25 & 0.15 & 0.25 & 0.07 & 0.20 \\
\hline
\end{tabular}

Примечания. 1 - доверительный интервал среднего значения выборки, включающей 33 пробы, с надежностью $\mathrm{P}=0.95 ; 2$ - жирным шрифтом выделены коэффициенты вариации Kvar с абсолютными значениями $>0.50$; 3 - минералы: Fsp - K-Na полевые шпаты; Ne - нефелин; Am - амфибол; Px - пироксен; Lop - лопарит; Evd эвдиалит; $4-\mathrm{A}_{\text {эф }}-$ общая эффективная удельная радиоактивность.

Корреляционный анализом установлено, что общими параметрами для данной многопараметрической системы являются рудные минералы - лопарит и эвдиалит. Породообразующие минералы взаимосвязаны со средней плотностью отходов обогащения.

В изучаемой геоэкологической системе по степени взаимосвязи выделяются следующие группы параметров: связанные и не связанные. Первая группа включает подгруппы А и Б.

Подгруппа А представлена показателями плотности - средней и истинной, содержанием средней фракции 0.25-0.50 мм $\left(\Sigma \mathrm{R}_{\mathrm{x}}=352=382\right)$. Подгруппа Б включает показатели содержаний радионуклидов ${ }^{232} \mathrm{Th}$ и ${ }^{226} \mathrm{Ra}$, содержания мелкой фракции 0.10-0.05 мм $\left(\left(\Sigma \mathrm{R}_{\mathrm{x}}=309-345\right)\right.$. То есть, показатели подгруппы А более взаимосвязаны, чем показатели подгруппы Б.

Группу слабо взаимосвязанных (независимых) параметров системы $\left(\Sigma \mathrm{R}_{\mathrm{x}}=78=227\right)$ включают показатели, которые распределяются по силе взаимосвязи в следующей последовательности от менее к более связаным: Evd $<$ фp. 0.25-0.1 мм $<$ Am $<$ Fsp $<$ Ne. Tо есть это группа наиболее распространенных и выдержанных по величине показателей минерального и зернового состава.

В изучаемой системе, при помощи фа МГК установлены четыре фактора.

Первый фактор включает практически все значимые нагрузки, за исключением нагрузки показателя содержания фракции 0.25-0.1 мм. Вклад его в общую дисперсию этой многопараметрической системы составляет $30.4 \%$, то есть почти её третьей части. Это - генеральный фактор. Он включает 6 нагрузок при факторах $\omega>0.50$. По максимальным значениям $\omega$ первый фактор условно можно назвать средне-плотностной - «торий-радиационный». Признаковая структура важнейших его важнейших показателей имеет следующий вид:

$$
\text { 1f (30.4) } 71 \mathrm{Th}_{232}, 70 \text { Аэф / -81 } \rho_{\mathrm{cp}},-70 \mathrm{~W}
$$

Второй фактор - характерный. Вклад его в общую дисперсию составляет 19.9 \%. Он включает 10 параметров с нагрузками при факторах $\omega>0.50$. 


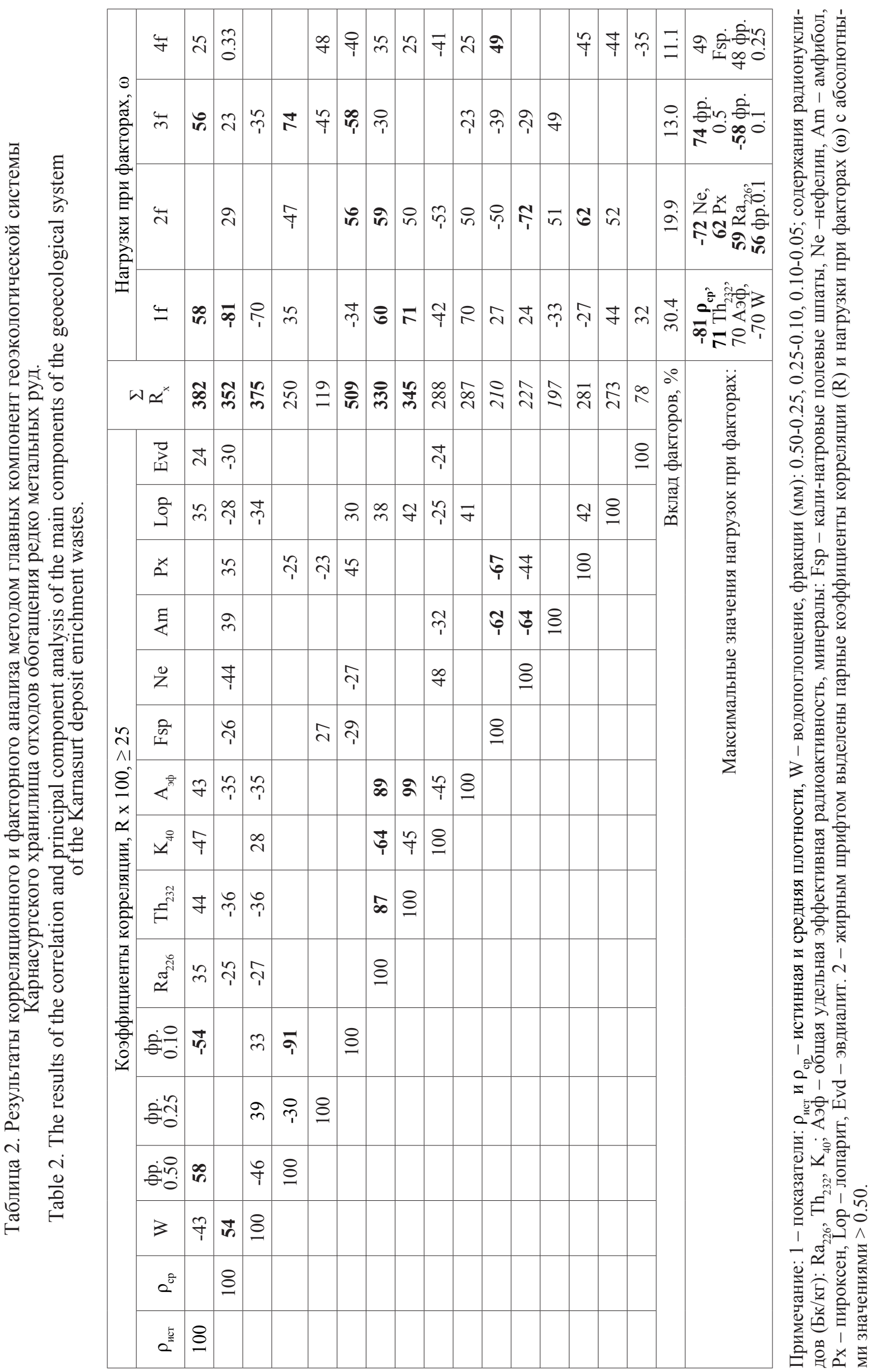


По максимальным значениям $\omega$ второй фактор условно можно назвать фактором «мезократовых нефелиновых сиенитов». Признаковая структура его важнейших показателей имеет следующий вид:

$$
\text { 2f (19.9) } 62 \text { Px, } \mathrm{Ra}_{226}, 56 \text { фр. 0.10-0.05 / -72 Ne, }-53 \mathrm{~K}_{40} \text {; }
$$

Третий фактор - локальный. Вклад его в общую дисперсию составляет 13.0 \%. Он включает 3 параметра с нагрузками при факторах $\omega>0.50$.

По максимальным значениям $\omega$ третий фактор условно можно назвать фактором «истинной плотности среднезернистой фракции 0.5-0.25 мм». Признаковая структура важнейших его важнейших показателей имеет следующий вид:

$$
3 f(13.0) 74 \text { фp.0.5-0.25, } 56 \rho_{\text {ист }} / /-58 \text { фр. 0.10-0.05; }
$$

Четвертый фактор - второстепенный. Вклад его в общую дисперсию составляет $11.1 \%$. Он включает 2 параметра с нагрузками при факторах $\omega \approx 0.50$. Наличие нагрузок при факторах менее 0.50 свидетельствует о том, что этот фактор слабо выражен. По максимальным значениям $\omega$ второй фактор условно можно назвать фактором «мезократовых нефелиновых сиенитов». Признаковая структура важнейших его важнейших показателей имеет следующий вид:

$$
\text { 4f (11.1) } 49 \text { Fsp, } 48 \text { фp. 0.25-0.10; }
$$

Взаимные связи между параметрами изучаемой системы хорошо описываются в координатах генерального, «средне-плотносно-торий-радиационного» и характерного, «мезократового нефелинового сиенита». Об этом свидетельствует сумма вкладов этих факторов, составляющая более $50 \%$ от общей дисперсии системы. Удовлетворительно описывается система в координатах генерального и локального фактора «среднезернистой фракции 0.5-0.25 мм», так как сумма вкладов этих факторов составляет третью часть общей дисперсии.

\section{Заключение}

Представлена методика мониторинга экологически опасных горно-промышленных объектов на примере хранилища отходов обогащения редкоземельных руд Карнасуртского месторождения.

Комплексные исследования инженерно-геологических свойств и вещественного состава текущих хвостов обогащения ООО «Ловозерский ГОК» показали, что уже на стадии складирования отходов наблюдается дифференциация вещества по крупности, плотности, а, следовательно, формируется неоднородность вещественного состава и содержаний ценных компонентов. Эти процессы будут усиливаться при хранении хвостов вследствие суффозии и гипергенных изменений минералов. С учетом того, что хвосты могут представлять интерес как техногенное месторождение РЗЭ, данные факты необходимо учитывать при разработке технологий его эксплуатации.

При помощи корреляционного и факторного анализа МГК определены основные показатели вещественного состава и структуры, влияющие на инженерно-геологические, физико-химические свойства отходов обогащения редко метального сырья. Установлен ториевый характер радиоактивности отходов. Это подтверждает результаты детальных геохимических исследований, проведенных на Ловозерском массиве (Ермолаева и др. 2007).

В Региональной лаборатории радиационного контроля ИХТРЭМС КНЦ РАН определены содержания радионуклидов ${ }^{226} \mathrm{Ra},{ }^{232} \mathrm{Th}$ и ${ }^{40} \mathrm{~K}$. Большинство проб отнесено к строительным материалам III класса, которые могут использоваться в дорожном строительстве вне населенных пунктов, в соответствии с нормативами ГОСТ 30108.

При переработке хвостов, как техногенного месторождения, флотацией с выделением лопаритового концентрата следует ожидать снижение удельной активности до нормируемых показателей для полевошпатового и нефелинового концентратов. Они могут найти применение как сырье в алюминиевой, керамической и стекольной отраслях промышленности, производстве строительных материалов и т.д.

Таким образом, проведенные исследования показали, что отходы обогащения редкометальных руд, складированные в ревдинском хранилище - это мелкозернистый пылеватый песок, со

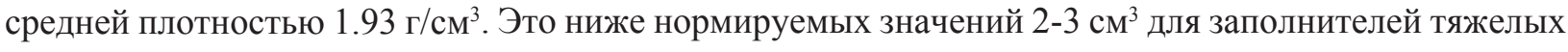


бетонов (ГОСТ 8267). Потому необходимо добавление более крупной фракции. Состав материаланефелин-эгирин-амфибол-полевошпатовый, включающий 1.7 и 0.6 мас. \% рудных минералов - лопарита и эвдиалита. Характер радиоактивности - радий-ториевый, 3-й класс радиоактивности (общая эффективная активность 842 Бк/кг). Это согласуется с детальными минералогическими исследованиями на Ловозерском массиве нефелиновых сиенитов (Ермолаева и др., 2007).

Авторы выражают благодарность студентке 4 курса по специальности «экология и природопользование» АФ МГТУ Ахмедовой А.А. за определения инженерно-геологических характеристик техногенных грунтов и инженеру первой категории Лаборатории регионального радиационного контроля ИХТРЭМС ФИЦ КНЦ РАН Икконену П.В. за проведение радиационного анализа проб.

Работа выполнена в рамках темы НИР №0226-2018-0001.

\section{Литература}

1. ГОСТ 5180-2015. Грунты. Методы лабораторного определения физических характеристик. М.: Стандартинформ. 2016. 19 с.

2. ГОСТ 8267-93 Щебень и гравий из плотных горных пород для строительных работ. Технические условия. М.: Стандартинформ. $2016.10 \mathrm{c}$.

3. ГОСТ 25100-2011. Грунты. Классификация. М.: Стандартинформ. 2019. 73 с.

4. ГОСТ 30108-94. Материалы и изделия строительные. Определение удельной эффективной активности естественных радионуклидов. М.: Стандартинформ. 2007. 14 с.

5. Доклад о состоянии и охране окружающей среды Мурманской области в 2017 году / МПР и экологии Мурманской области. Мурманск: ООО «Рекламное агенство ХХІ век». 2018. 165 с.

6. Ермолаева В.Н., Пеков И.В., Чуканов И.В., Задов А.Е. Ториевая минералогия в высокощелочных пегматитах и гидротермалитах Ловозерского массива (Кольский полуостров) // ЗРМО. Ч. 136. № 1. 2007. С. 3-25.

7. Лащук В.В., Мельник Н.А., Суворова О.В., Лёвкин А.В., Мотина А.В. Особенности гранулометрического и минерального составов, инженерно-геологических и радиационно-гигиенических свойств лежалых хвостов вермикулитовой обогатительной фабрики ОАО «Ковдорслюда» // Научные основы химии и технологии переработки комплексного сырья и синтеза на его основе функциональных материалов. Сб. докл. Всерос. конф. с междунар. участием. Ч. 2. Апатиты: изд-во КНЦ РАН. 2008. С. 163-167.

8. Лащук В.В., Суворова О.В., Макаров Д.В., Бокарева В.А. Исследование отходов обогащения руд горнопромышленного комплекса Мурманской области в качестве термохимического сырья для производства стекла и керамики // Труды VIII Ферсмановской научной сессии. Апатиты: Изд-во К \& M. 2011. С. 259-269.

9. Ломтадзе В.Д. Инженерная геология: инженерная петрология. 2-е изд. доп. и перераб. Л.: Недра. 1984. 511 c.

10. Пожиленко В.И., Гавриленко Б.В., Жиров Д.В., Жабин С.В. Геология рудных районов Мурманской области. Апатиты: Изд. Кольского НЦ РАН, 2002. 359 с.

11. Lottermoser B.G. Recycling, reuse and rehabilitation of mine wastes // Elements. 2011. V. 7. N 6. P. 405-410. 